\title{
A Unified Account of Two Vowel Devoicing Phenomena: the Case of Cheyenne
}

\author{
Rachel Vogel \\ Cornell University
}

\section{Introduction}

Vowel devoicing has been the subject of typological investigation as far back as Greenberg 1969, and more recently in Gordon 1998 and Chitoran and Marsico 2010. This work has demonstrated that both phonetic and phonological processes of vowel devoicing across the world's languages typically fit into one of the following two categories in terms of the environments in which they occur: a) adjacent to voiceless consonants, and b) adjacent to the right edge of a prosodic domain. It is also possible for one process to fit into both categories at the same time, as is the case in Brazilian Portuguese, in which word-final devoicing occurs only in vowels that are both adjacent to the right edge of a word and to a voiceless consonant (Walker and Mendes 2019). Aside from some domain-final cases, however, vowel devoicing adjacent to voiceless consonants is typically a domain-span process, targeting any vowel in the right segmental environment (with limited exceptions noted in Section 2 of this paper).

This paper investigates two vowel devoicing processes in Cheyenne, an Algonquian language spoken in Montana and Oklahoma (Leman 2011). The first process, phrase-final devoicing (PFD), occurs in any wordfinal vowel at the end of what has been described as the phonological phrase (e.g., [návóómo méfe] 'I see the woodtick,' Leman and Rhodes 1978). It is thus consistent with typological expectations and, as will be discussed in this paper, phonetically grounded. The second process, referred to as penultimate devoicing (PD) in the Cheyenne literature, occurs before voiceless consonants, but only in the penultimate syllable of some words (e.g., in [vóhpoma?ohtse] 'salt' but not [moho?ohtse] 'part of Ursa Major,' Fisher et al. 2017)). In this way, it is at first glance neither typologically expected nor phonetically motivated. It also seems to lack a phonological motivation, given the apparently arbitrary, restricted prosodic environment in which it occurs.

I propose a new, unified, analysis of these two vowel devoicing processes, in which both are seen as instances of domain-final devoicing. Adopting a Stratal Optimality Theory approach, I demonstrate that in order to correctly predict the application of PD, it must occur at a stage in the phonology in which the target vowels are in the word-final syllable. This environment is later obscured on the surface by a process of (postlexical) vowel epenthesis. I also show that both processes can be attributed to the same family of positional markedness constraints; the different segmental environments in which the two processes occur result simply from different interactions between these markedness constraints and a faithfulness constraint against insertion of phonological features.

In the sections that follow, I first provide background on vowel devoicing cross-linguistically and on Cheyenne phonology in Section 2. I then describe the major vowel devoicing patterns in Cheyenne focusing on the two domain-final processes in Section 3, and propose a unified analysis of both within Stratal OT in Section 4. Section 5 is the conclusion.

\section{Background}

2.1 Vowel devoicing cross-linguistically: distribution and phonological and phonetic accounts Voiceless vowels are thought to be relatively rare cross-linguistically and phonologically marked relative to voiced vowels (Gordon 1998; Tsuchida 2001); however, they are a common areal feature in the Plains region

\footnotetext{
${ }^{*}$ I would like to acknowledge the Cheyenne language and speakers and everyone who has done work to document the language. Additionally, I would like to thank members of the Cornell Linguistics Department and attendees of AMP 2020 for their feedback on this work.
} 
of North America where Cheyenne is spoken (Ladefoged and Maddieson 1996; Oberley and Kharlamov 2015). They have also been attested across a wide variety of language families and geographic regions, including in East Asia, South Asia, Oceanea, Europe, Africa, the Middle East, and elsewhere in North and South America (Greenberg 1969). While the patterns and realizations of vowel devoicing vary crosslinguistically (Gordon 1998), relatively strong typological generalizations and implicational relations hold for these phenomena. For instance, it has been observed that devoicing of certain vowel qualities and quantities implies devoicing of others, and that devoicing in certain prosodic positions implies devoicing in other positions. Another generalization, which is the focus of this paper, is that most, if not all, vowel devoicing processes involve adjacency either to other voiceless consonants or to the edge of a prosodic domain, or both (Greenberg 1969; Gordon 1998).

As mentioned in Section 1, vowel devoicing adjacent to voiceless segments typically occurs as a domainspan process. That is, while it may be blocked by suprasegmental properties such as stress or high tone, it otherwise applies to any vowel in the right segmental environment, irrespective of prosodic position within the relevant domain (Gordon 1998). This type of vowel devoicing is typically accounted for phonologically as a form of assimilation, with a laryngeal feature that spreads from an adjacent voiceless segment (e.g., Cho 1993; Tsuchida 2001). ${ }^{1}$ It is also understood to be phonetically grounded in terms of gestural overlap between a glottal abduction gesture associated with the voiceless segment and a glottal adduction gesture associated with the voiced vowel (e.g., Beckman 1996; Gordon 1998; Chitoran and Iskarous 2008).

As for vowel devoicing adjacent to prosodic boundaries, it is typically the right-hand boundary that is important. In fact, Gordon (1998) notes that domain-final devoicing is the most common pattern among the languages with vowel devoicing that he surveyed. Within the broad category of domain-final devoicing, the relevant prosodic domains vary. In some languages, devoicing occurs only at the right edge of large domains (e.g., phrases or utterances), whereas in other languages, devoicing can also occur at the end of smaller domains, like the word (Greenberg 1969; Gordon 1998). The relationship between prosodic and segmental factors also varies for these processes. In some languages, domain-final devoicing occurs only in vowels that are also adjacent to voiceless consonants; in others, it can occur without an adjacent voiceless segment as long as the prosodic conditions are met (Gordon 1998).

When domain-final devoicing occurs adjacent to a voiceless consonant, phonetic and phonological accounts based on gestural overlap and feature spreading may still be relevant. In cases without adjacent voiceless consonants, however, the accounts discussed above are not applicable. Rather, from a phonetic perspective, processes of domain-final devoicing are often attributed to the decrease in subglottal air pressure over the course of an utterance, making voicing more difficult to produce toward the end of a long stream of speech (Dauer 1980; Gordon 1998; Kilbourn-Ceron and Sonderegger 2018). This would of course be more likely at the ends of larger domains, in which there is more time for the subglottal air pressure to decrease. An alternative phonetic explanation for devoicing in pre-pausal environments is the anticipation of an open or relaxed glottis during silence or rest (Smith 2003). This explanation is also more viable at the ends of larger prosodic domains where pauses are more likely. Word-final vowel devoicing is therefore the one category without phonetic grounding, given that words in non-final positions of phrases and utterances should not always exhibit decreased subglottal air pressure and or be followed by a pause.

While word-final vowel devoicing lacks a phonetic motivation and must therefore be handled in the phonology, most existing phonological work on vowel devoicing focuses on processes adjacent to voiceless consonants (e.g., Lipski 1990 on Ecuadorian Spanish; Cho 1993 on Japanese, Comanche, and Acoma; Tsuchida 1997, 2001 on Japanese). Meanwhile, relatively little phonological attention is paid to domain-final devoicing, including word-final processes. An exception to this is Louie 2010, which provides an Optimality Theory account of word-final vowel devoicing in Northern Paiute. This analysis attributes vowel devoicing to the insertion of a [spread glottis] feature on word-final vowels to satisfy an alignment constraint requiring that the right edge of a word be aligned with the right edge of a [spread glottis] feature.

It should also be noted that within phonological accounts of vowel devoicing, the particular laryngeal feature involved has been debated. Earlier analyses made reference to [-voice] (e.g., McCawley 1968 for Japanese), but more recently, arguments have been made in favor of [spread glottis] (Cho 1993; Tsuchida

\footnotetext{
${ }^{1}$ Tsuchida's (2001) analysis also involves insertion of the relevant laryngeal feature under some circumstances.
} 
1997, 2001; Louie 2010). Though it is not the focus of the present paper, I will briefly discuss in Section 3 evidence for the laryngeal representations that I assume for Cheyenne voiceless vowels.

2.2 Cheyenne This section provides an introduction to several aspects of Cheyenne phonology, focusing on its phoneme and tone inventories, as well as some important phonotactic constraints. Cheyenne contains a relatively small phoneme inventory with ten consonants, shown in Table 1 (along with two additional allophones in parentheses), and three vowels, shown in Table 2 (Leman 1980, 2011). The symbols in angled brackets in the first table are Cheyenne orthography versions of the IPA symbols to their left in the same cells. The sources of data cited in this paper follow several different orthographic conventions, which include IPA and Cheyenne orthography versions of some of the same segments. For consistency, the rest of this paper uses IPA symbols.

Table 1. Cheyenne consonant inventory (based on Leman 1980, 2011)

\begin{tabular}{|l|l|l|l|l|l|}
\hline & Bilabial & Dental & Post-Alveolar & Velar & Glottal \\
\hline Stops & $\mathrm{p}$ & $\mathrm{t}$ & $\mathrm{k}$ & & $\mathrm{P}<{ }^{\prime}>$ \\
\hline Affricates & & $\mathrm{(ts})$ & & & \\
\hline Fricatives & $\mathrm{v}$ & $\mathrm{s}$ & $\mathrm{f}<\mathrm{s}>$ & $\mathrm{x})$ & $\mathrm{h}$ \\
\hline Nasals & $\mathrm{m}$ & $\mathrm{n}$ & & & \\
\hline
\end{tabular}

Table 2. Cheyenne vowel inventory (based on Leman 1980, 2011)

\begin{tabular}{|l|l|l|l|}
\hline & Front & Central & Back \\
\hline Mid & e & & o \\
\hline Low & & a & \\
\hline
\end{tabular}

As can be seen in Table 1, all obstruents are voiceless in Cheyenne, except perhaps for $/ \mathrm{v} /$. This consonant is transcribed as a voiced fricative in Leman's $(1980,2011)$ grammar but may be better understood as a sonorant (like $/ \mathrm{w} /$ or $/ \mathrm{v} /$ ) given the absence of other voiced obstruents and the absence of a voiceless fricative in the same place of articulation. ${ }^{2}[\mathrm{x}]$ is an allophone of $/ \mathrm{g} /$ and $/ \mathrm{h} /$, said to surface from the former when followed by [a] or [o], and from the latter when followed by another [h] (Leman 2011). [ts] is an allophone of /t/ that surfaces before [e]. As can be seen in Table 2, there are only two contrastive vowel heights, and all vowels are underlyingly voiced. The voiceless vowels discussed in the rest of this paper appear on the surface in predictable environments due to several phonological processes. Cheyenne also has two contrastive tones: high, which is marked with an acute accent in this paper, and low, which is not marked here, consistent with the orthography.

Turning to phonotactics, word-internally, Cheyenne allows certain sequences of two consonants, the first of which is typically a glottal stop or fricative. This is illustrated in (1) and (2) below; the clusters are shown in bold.

[mąhtao?keme] 'coffee bean'

(Fisher et al. 2017)

$$
\text { [he?éka?ęJkóne] 'girl' }
$$

(Fisher et al. 2017)

\footnotetext{
${ }^{2}$ In fact, /v/ has also been described by Leman (2011) as variably realized as [v], [ß], or [w], depending on the word. Obstruents and sonorants behave differently in word-final position (as described later in this section), offering a potential way to categorize ambiguous consonants. To my knowledge, however, there are no instances of word-final $/ \mathrm{v} /$ to test this.
} 
Word-finally, on the other hand, codas are not permitted. Underlying word-final sonorants delete and underlying word-final obstruents are followed on the surface by an epenthetic $<\mathrm{e}>$. Both processes can be seen in alternations involving nouns, such as those shown in (3) - (5) below. The (a) forms of the examples are plural nouns, in which a root is followed by one of several possible plural suffixes. (Morpheme breaks are shown with dashes in these examples.) The (b) forms are singular versions of the same nouns, which consist of only the root without a suffix. It can be seen from the plural forms that all three noun roots end in a consonant. In 'cats' in (3a), the plural suffix /-o/ follows an [n], indicating that the root and singular form of 'cat' end in an underlying nasal. Similarly, the plural suffixes in (4a) and (5a) follow [x] and [t], indicating that 'axe' and 'snake' end underlyingly in a fricative and a stop, respectively. It can be seen in the (b) examples, however, that these root-final consonants do not appear in word-final environments at the end of the singular forms. The nasal disappears in (3b) and the fricative and stop are followed by [e] in (4b) and (5b). The root-final consonants are bolded in all five forms in which they appear, and the epenthetic $<\mathrm{e}>$ is underlined in (4b) and (5b).

$$
\begin{aligned}
& \text { a. [póéson-o] 'cats' } \\
& \text { b. [póéso] 'cat' }
\end{aligned}
$$

a. [hóhkóx-ęste] 'axes'

b. [hóhkoxe] 'axe'

(Fisher et al. 2017)

a. [jéfenovot-o] 'snakes'

b. [Jéfenovọtse] 'snake'

(Leman 1980)

As will be seen later, the process of word-final $<\mathrm{e}>$ epenthesis after obstruents is critical for understanding the vowel devoicing patterns analyzed in this paper.

\section{Vowel devoicing}

Cheyenne exhibits extensive vowel devoicing resulting from three main processes. While the focus of this paper is on the two domain-final vowel devoicing processes, it is also important to understand how these fit into the larger picture of Cheyenne phonology, including the third vowel devoicing pattern, a domain span process. In particular, consideration of this third pattern informs the featural accounts of the two domainfinal processes of focus. This section describes all three vowel devoicing patterns based on the categories and terminology of previous literature (e.g., Leman and Rhodes 1978) and highlights some implications from these descriptions for the phonological analysis developed in this paper. All voiceless vowels in this section and the rest of this paper are marked with the standard IPA diacritic, a circle below the vowel, as in [a]. It is not uncommon for words to contain multiple voiceless vowels resulting from different processes, so the vowels of interest in each example are shown in bold. (Other, non-bolded, voiceless vowels result from different processes.)

3.1 Phrase-final devoicing Phrase-final devoicing, or PFD (Leman and Rhodes 1978), can be characterized as a domain limit process (Selkirk 1980; Vogel 1984), occurring in only one syllable at the right edge of a prosodic domain. Specifically, it is described as applying to all vowels at the end of a phonological phrase in Leman 1981, and before a pause in Leman 2011. The phonological phrase has not been otherwise defined in Cheyenne, and a more thorough exploration of prosodic structure in the language is outside the scope of this paper. What is important for the present purposes is that there is some phrasal domain at the end of which all word-final vowels devoice.

The basic pattern of PFD is illustrated below in (6). It can be seen that the final vowel of návóómo devoices in (6a), where it is phrase-final, but not in (6b), where it is phrase-medial. In addition, in (6b), the final vowel of the second word, méfe, exhibits phrase-final devoicing as expected.

a. [návóómo] 'I see him'

b. [návóómo méfe] 'I see the woodtick'

(Leman and Rhodes 1978) 
As noted in Section 2, domain-final processes are the most common form of vowel devoicing crosslinguistically. Additionally, those that occur in large domain-final positions like PFD have multiple phonetic explanations, including aerodynamic pressure making voicing more difficult toward the end of a long stream of speech, and anticipatory glottal opening before a pause. Thus, PFD can be understood as consistent with typological expectations as well as phonetically grounded.

Like many domain-final vowel devoicing processes, PFD does not require an adjacent voiceless consonant. Due to the phonotactic constraint on word-final segments discussed in Section 2, phrase-final syllables are always open, so the process cannot be conditioned by a voiceless consonant to the right of the vowel. (This is in contrast to the other two processes discussed later in this section.) Additionally, (6a) demonstrates that PFD can occur in vowels following nasals, in which case the devoiced vowel is not preceded by a voiceless consonant either. Thus, from a phonological perspective, feature spreading is not a possible source of voicelessness for PFD. Rather, this process must be accounted for in terms of insertion of a laryngeal feature at phrase boundaries.

3.2 Penultimate devoicing The second vowel devoicing process has been referred to as penultimate devoicing or PD in the previous literature (e.g., Leman and Rhodes 1978). This process affects surface penultimate vowels followed by voiceless consonants in some words ending in [e], as shown in (7) and (8) below. The process never occurs in penultimate vowels followed by a voiced consonant such as a nasal (e.g., (9)).

$$
\text { [hóhkoxe] 'axe' }
$$

(Fisher et al. 2017)

$$
\text { [he?ogtse] 'neck' }
$$

$$
\text { [nęstámane] 'our (incl.) food' }
$$

(Fisher et al. 2017)

Because PD occurs only before voiceless consonants, it can be accounted for in terms of assimilation or feature spreading, unlike PFD. It is not immediately obvious, though, from either typological or phonological perspectives, why assimilation would be restricted to such a seemingly arbitrary syllable as the penult. As mentioned in Section 2, assimilatory devoicing typically occurs either as a domain span process or only in domain-final positions. It can be seen, however, that the surface environment is not a sufficient predictor of when PD occurs (Leman and Rhodes 1978). This is illustrated in (10) and (11) below, which contain nearly identical penultimate and final syllables, underlined in both examples. The only difference is that the penultimate vowel is devoiced in (10) but voiced in (11).

$$
\text { [vóhpoma?ohtse] 'salt' }
$$

(Fisher et al. 2017)

$$
\text { [mohopohtse] 'part of Ursa Major' }
$$

(Fisher et al. 2017)

Leman and Rhodes (1978) propose that the process only occurs in words in which the final [e] is epenthetic. A comparison of singular and plural forms of nouns offers support for their proposal. As explained in Section 2 , noun roots that end underlyingly in an obstruent are followed by an epenthetic $<\mathrm{e}>$ in their singular forms, where the right edge of the root coincides with the right edge of the word. There is no corresponding [e] in their plural forms, on the other hand, where roots are followed by a plural suffix. This is illustrated again in (12) below. In contrast, there are other noun roots that end in an [e] in both singular and plural forms, in which case the [e] must be analyzed as underlying rather than epenthetic. This latter case is shown in (13). The root-final [e] is underlined in all forms in which it appears. It is present in (12a) and both versions of (13), but not in (12b).

$$
\text { a. [seo?otse] 'ghost' }
$$

b. [séot-o] 'ghosts'

(Leman 2011)
a. [nótaxe] 'warrior'
b. [nótaxe e-o?o] 'warriors'

(Fisher et al. 2017) 
Crucially, singular nouns ending with an epenthetic [e], such as 'ghost,' exhibit PD, whereas singular nouns ending with an [e] that is present underlyingly, such as 'warrior,' do not. Leman and Rhodes account for this pattern with rule ordering, such that PD occurs prior to $<\mathrm{e}>$ epenthesis and targets vowels preceding wordfinal voiceless obstruents. Since $<\mathrm{e}>$ epenthesis occurs after all obstruents, and all or most obstruents are voiceless, the words exhibiting PD are precisely also those that undergo $<\mathrm{e}>$ epenthesis. For this reason, the word-final environment of PD is consistently obscured on the surface. While the present paper does not use ordered rules, the basic observation of Leman and Rhodes still holds. That is, in order to predict when the process will occur, the analysis must make reference to prosodic structure prior to $<\mathrm{e}>$ epenthesis. This identifies PD as a domain limit vowel devoicing process like PFD, targeting vowels at the right edge of a word. In this way, the process is not, in fact, as typologically unexpected nor as phonologically unmotivated as it first appears. Nevertheless, as a word-final devoicing process, it is still not phonetically motivated (see the discussion in Section 2).

Finally, it is important to note that there is also evidence for ordering between PD and PFD. While PD must occur before $<\mathrm{e}>$ epenthesis, epenthetic vowels can undergo PFD. Thus, words with epenthetic $<\mathrm{e}>$ can exhibit two domain-final devoicing processes on consecutive syllables, as shown in (14).

$$
\text { [néméhotạtse] 'I love you' }
$$

(Fisher et al. 2017)

This indicates that PFD must occur at a later stage in the phonology than PD, in which epenthetic vowels are present. This will be taken as evidence in the analysis proposed in this paper that both epenthesis and PFD are post-lexical processes.

3.3 Prepenultimate devoicing The third vowel devoicing process is referred to as prepenultimate devoicing, or PPD (Leman and Rhodes 1978). PPD is not a focus of this paper, however, as mentioned at the beginning of this section, it is important to discuss briefly since it informs the analysis of the other two processes. PPD affects low tone vowels followed by voiceless fricatives, as illustrated in (15) - (17) below. As a domain span process, it can occur throughout most of the word. In fact, in (15), it applies in three syllables in a row.

$$
\text { [mạnnohtsesstovotse] 'when you ask him' }
$$

(Leman 1981)

$$
\text { [moxéheo?o] 'broom' }
$$

(Fisher et al. 2017)

$$
\text { [hePéka?êfkóne] 'girl' }
$$

(Fisher et al. 2017)

PPD is blocked in the underlying penultimate syllable of the word, as shown in (18), where the penultimate vowel bears low tone and is followed by a voiceless fricative but nevertheless does not devoice. Example (19), which ends in an epenthetic $<\mathrm{e}>$, demonstrates that it is the underlying rather than surface prosodic structure that is important. That is, it is the surface antepenultimate syllable (underlying penult) that resists devoicing, rather than the surface penult (Leman and Rhodes 1978). Thus, the prosodic conditioning of PPD, like that of $\mathrm{PD}$, must be based on a stage in the phonology prior to $<\mathrm{e}>$ epenthesis.

$$
\text { [kahamaxe] 'stick' }
$$

(Fisher et al. 2017)

$$
\text { [táhoxe?ęstónestọotse] 'desk' }
$$

It should be noted that the underlying word-final syllables that meet the conditions for PPD (i.e. low tone vowel followed by a voiceless fricative) are a subset of those that meet the conditions for PD, and always devoice. Therefore, there is really only evidence that "prepenultimate devoicing" is blocked in the penultimate syllable (as opposed to the penultimate and final syllables as the name suggests). The fact that the penultimate syllable is the only position in the word that resists a domain-span process of vowel devoicing when all segmental and tonal conditions are met suggests that it has a privileged status relative to the rest of the word. While Cheyenne is not a canonical stress language, I propose that the resistance to devoicing in the 
penultimate syllable reflects word-level prominence in that position (consistent with arguments in Milliken 1983 and Bogomolets 2019).

The most important aspect of PPD for the present purposes is the segmental environment in which it applies. While PPD occurs before voiceless fricatives, as shown above, it does not occur before voiceless stops or affricates, as can be seen below in the second syllable of (20) and the first syllable of (21). Thus, like PD, PPD only applies adjacent to voiceless consonants, and may be analyzed in terms of feature spreading. However, the two processes involve different sets of voiceless consonants, indicating that the same laryngeal feature cannot be used to account for both processes.

$$
\text { [ómotóme] 'air' }
$$

(Fisher et al. 2017)

$$
\text { [matsénesstse] 'kingfisher' }
$$

(Fisher et al. 2017)

Specifically, PPD requires a laryngeal feature specified only for voiceless fricatives, whereas PD requires a different feature, which must be specified for all voiceless consonants. In this way, the pattern of PPD constrains the analysis of domain-final devoicing developed in this paper. I propose that voiceless fricatives bear a [spread glottis] feature, which spreads in PPD. (See Vaux 1998 and Vaux and Miller 2011 for arguments that [spread glottis] is specified for voiceless fricatives but not for other unaspirated voiceless consonants cross-linguistically.) Meanwhile, all voiceless consonants bear a [-voice] feature, which spreads in PD.

3.4 Summary Before turning to a more complete phonological analysis of phrase-final and penultimate devoicing in the next section, I summarize the prosodic and segmental environments in which all three processes occur, and their implications for the phonological analysis, in Table 3.

Table 3. Summary of three Cheyenne vowel devoicing processes

\begin{tabular}{|l|l|l|l|}
\hline & PPD & PD & PFD \\
\hline $\begin{array}{l}\text { Prosodic } \\
\text { distribution }\end{array}$ & Domain span & Domain (word) final & Domain (phrase) final \\
\hline Ordering & $\begin{array}{l}\text { Prior to }<\mathrm{e}> \\
\text { epenthesis }\end{array}$ & Prior to <e > epenthesis & $\begin{array}{l}\text { At same time as or after } \\
<\mathrm{e}>\text { epenthesis }\end{array}$ \\
\hline $\begin{array}{l}\text { Segmental } \\
\text { environment }\end{array}$ & $\begin{array}{l}\text { Before voiceless } \\
\text { fricatives }\end{array}$ & $\begin{array}{l}\text { Before any voiceless } \\
\text { consonant }\end{array}$ & Any \\
\hline $\begin{array}{l}\text { Source and type of } \\
\text { laryngeal feature }\end{array}$ & Spreading of [SG] & Spreading of [-voice] & $\begin{array}{l}\text { Insertion of laryngeal } \\
\text { feature }\end{array}$ \\
\hline
\end{tabular}

As discussed above and shown in Table 3, PD and PFD can both be analyzed as domain-final processes. Due to $<\mathrm{e}>$ epenthesis after word-final obstruents, the domain-final environment of PD is obscured on the surface. At first glance, it thus seems to occur in a somewhat arbitrary and typologically unexpected, restricted position. In order to predict the application of PD and analyze it as a domain-final process, it must occur earlier in the phonology than $<\mathrm{e}>$ epenthesis. PFD, on the other hand, can target epenthetic vowels, and therefore must occur either at the same time as, or after, epenthesis.

The other crucial difference between PD and PFD has to do with the segmental environments in which they occur. While PFD can occur in any segmental environment, PD occurs only before voiceless consonants. I have proposed that this reflects two different sources of the laryngeal feature responsible for devoicing: spreading from a consonant to the preceding vowel for PD and insertion for PFD.

The fairly independent pattern of PPD is relevant in this context, because it provides evidence for the particular laryngeal features involved in Cheyenne vowel devoicing. Specifically, I propose that PPD involves [spread glottis] whereas PD involves [-voice]. Since PFD results from feature insertion rather than 
spreading, the local segmental environments in which it occurs do not provide evidence for which laryngeal feature is involved. As I will demonstrate in the following section, however, both PD and PFD can be attributed to the same family of positional markedness constraints against voiced vowels in domain-final syllables. I will therefore assume, given no counter evidence, that both processes involve the same laryngeal feature, [-voice].

\section{Stratal Optimality Theory analysis of domain-final vowel devoicing}

This section provides a formal account of the two domain-final vowel devoicing processes, referred to in the previous literature and in Section 3 as penultimate and phrase-final devoicing. I attribute both processes to the same family of positional markedness constraints against domain-final voiced vowels. These constraints are defined for the word and phonological phrase domains in (22) and (23), respectively. Given that penultimate devoicing is actually treated as a word-final process in the proposed analysis, from this point forward, I will refer to it as "word-final devoicing."

$$
\begin{aligned}
& \left.* \mathrm{~V}_{[+ \text {voice] }} \mathrm{C}_{0}\right]_{\mathrm{wd}} \text { - no voiced vowels in the final syllable of a word } \\
& \left.* \mathrm{~V}_{[+ \text {voice] }} \mathrm{C}_{0}\right]_{\mathrm{PhPh}} \text { - no voiced vowels in the final syllable of a phrase }
\end{aligned}
$$

It was demonstrated in Section 3 that word-final and phrase-final devoicing differ in two crucial respects, which must be accounted for in the phonological analysis. First, they exhibit different orderings with respect to $<\mathrm{e}>$ epenthesis, with word-final devoicing occurring prior to epenthesis, and phrase-final devoicing occurring either at the same time as or after epenthesis. Second, they involve different sources of the laryngeal feature responsible for devoicing, which I assume is [-voice] for both processes. That is, word-final devoicing involves spreading of [-voice] from a following voiceless consonant, whereas phrase-final devoicing involves insertion of [-voice]. I will demonstrate in this section that both of these differences can be accounted for straightforwardly within the framework of Stratal OT (Kiparsky 2000; Bermúdez-Otero 2018). The apparent ordering can be accounted for with the distribution of vowel devoicing across two different strata. Specifically, penultimate devoicing is accounted for at the word stratum, whereas $<\mathrm{e}>$ epenthesis and phrasefinal devoicing must occur at the phrase stratum (roughly corresponding to the post-lexical level of Lexical Phonology). The different sources of [-voice] can be attributed to different constraint rankings between the positional markedness constraints in (22) and (23) and a faithfulness constraint against feature insertion, DEP[F]. Two key aspects of the Stratal OT framework for this analysis are that a) the output of one stratum serves as the input to the next stratum, and b) it is possible for a constraint to be promoted to an undominated status from one stratum to the next.

4.1 Word-final devoicing and phonotactics at the word stratum Considering first word-final devoicing, the analysis must account for the fact that vowels in word-final syllables only devoice when followed by a voiceless consonant; in other words, only when a [-voice] feature is present in the input and can spread leftward to the preceding vowel. This can be achieved with a constraint ranking of DEP[F] $>>$ $\left.* \mathrm{~V}_{[+ \text {voice }]} \mathrm{C}_{0}\right]_{\mathrm{wd}}$, where $\mathrm{DEP}[\mathrm{F}]$ states that features may not be inserted. The interaction of these constraints is illustrated in the tableaux in (24) and (25) below. Recall that these tableaux illustrate only the phonology that takes place at the word stratum. Thus, the winners are intermediate forms rather than surface forms and will go through another round of phonology at the phrase stratum.

In (24), /he?ot/ 'neck' undergoes word-final devoicing because the final vowel is followed by a voiceless consonant $/ t /$, which I assume is specified for [-voice]. The winning candidate (b) can therefore satisfy $\left.{ }^{*} \mathrm{~V}_{[+ \text {voice }]} \mathrm{C}_{0}\right]_{\mathrm{wd}}$ without violating the higher ranked DEP[F]. In (25), on the other hand, the final vowel of /póésono/ 'cats' does not devoice because there is no adjacent voiceless consonant with a [-voice] feature that can spread to the vowel. That means that in order to satisfy $\left.* \mathrm{~V}_{[+ \text {voice }]} \mathrm{C}_{0}\right]_{\mathrm{wd}}$, a feature would need to be inserted, violating DEP[F], as seen in candidate (b) in this second tableau. It can also be seen that $\left.* \mathrm{~V}_{[+ \text {voice }} \mathrm{C}_{0}\right]_{\text {wd }}$ must outrank two other constraints, Ident[Lar] (abbreviated $\left.\operatorname{ID}[\mathrm{Lar}]\right)$ and $* \mathrm{~V}_{\text {[-voice] }}$, which require that laryngeal features in the output be faithful to the input and prohibit voiceless vowels in the output respectively. 
(24) Word-final devoicing in /he?ot/ $\rightarrow$ he?ot 'neck' (word stratum)

\begin{tabular}{|c||l|l|l|l|}
\hline he?ot & DEP[F] & $\left.* \mathrm{~V}_{[+ \text {voice }} \mathrm{C}_{0}\right]_{\mathrm{wd}}$ & ID $[$ Lar $]$ & $* \mathrm{~V}_{\text {[-voice] }}$ \\
\hline \hline a. he?ot & & $* !$ & & \\
\hline b. he?ot & & & $*$ & $*$ \\
\hline
\end{tabular}

(25) No penultimate devoicing in /póésono/ $\rightarrow$ póésono 'cats' (word stratum)

\begin{tabular}{|c||l|l|l|l|}
\hline póésono & $\mathrm{DEP}[\mathrm{F}]$ & $\left.* \mathrm{~V}_{[+ \text {voice }} \mathrm{C}_{0}\right]_{\mathrm{wd}}$ & $\mathrm{ID}[\mathrm{Lar}]$ & $* \mathrm{~V}_{\text {[-voice] }}$ \\
\hline \hline a. póésono & & $*$ & & \\
\hline b. póésono & $* !$ & & $*$ & $*$ \\
\hline
\end{tabular}

It should be noted that word-final devoicing does not occur in syllables with voiceless onsets if they do not also have a voiceless coda. For example, there is no word-final devoicing in /mo?hekan/ $\rightarrow$ [mo?heka] 'moccasin' (Leman 2011). In fact, while there are several cases of regressive assimilation in Cheyenne (e.g., [spread glottis] assimilation in PPD), I am not aware of any cases of progressive assimilation. We might therefore assume that there is a general constraint preventing rightward spreading of features (e.g., *RightSpreading), which outranks $\left.* \mathrm{~V}_{[+ \text {voice }} \mathrm{C}_{0}\right]_{\text {wd. }}$. Thus, in words such as $/$ mo?hekan/, word-final devoicing would still require feature insertion and be prohibited by DEP[F].

The second issue to be addressed at the word stratum is the status of word-final consonants. Final codas must be permitted at this stage of the phonology in order for word-final devoicing to target vowels that are indeed in word-final syllables and followed by voiceless consonants. $<\mathrm{e}>$ epenthesis therefore must take place later on, at the phrase stratum. I will attribute the avoidance of word-final codas to a constraint $\left.{ }^{*} \mathrm{CODA}\right]_{\text {wd. }}$ In order to avoid deletion of or $<\mathrm{e}>$ epenthesis after final obstruents at the word stratum, this constraint must be outranked by faithfulness constraints, DEP and MAX(obstruent). The role of these constraints along with the role of constraints responsible for word-final devoicing are illustrated in (26).

(26) Word-final devoicing and preservation of final coda in /he?ot/ $\rightarrow$ he?ot 'neck' (word stratum)

\begin{tabular}{|c|c|c|c|c|c|c|c|}
\hline he?ot & DEP & MAX(obs) & $\left.{ }^{*} \mathrm{CODA}\right]_{\mathrm{wd}}$ & $\mathrm{DEP}[\mathrm{F}]$ & $\left.* \mathrm{~V}_{[+ \text {voice }} \mathrm{C}_{0}\right]_{\mathrm{wd}}$ & ID[Lar] & $* \mathrm{~V}_{\text {[-voice] }}$ \\
\hline a. he?ot & & & $*$ & & $* !$ & & \\
\hline b. he?ot & & & * & & & * & * \\
\hline c. he?otse ${ }^{3}$ & $* !$ & & & & * & & \\
\hline d. he?o & & $* !$ & & & * & & \\
\hline
\end{tabular}

There is no evidence to determine when deletion of final sonorants occurs. For simplicity, I assume that this too occurs at the phrase stratum. This means that regular MAX must also outrank *CODA] $]_{\text {wd }}$ at the word stratum to prevent deletion of sonorants.

4.2 Phrase-final devoicing and phonotactics at the phrase-stratum Turning to the phrase-stratum, $\left.{ }^{*} \mathrm{CODA}\right]_{\text {wd }}$ must be promoted to an undominated status to ensure that word-final codas are eliminated at this stage of the phonology. Specifically, a ranking of $*$ CODA] $]_{w d}, \operatorname{MAX}$ (obstruent) $>>$ DEP $>>$ MAX is required to get epenthesis after obstruents, but deletion of sonorants. The interaction of *CODA $]_{\mathrm{wd}}, \mathrm{MAX}$ (obstruent), and DEP is illustrated for /he?ot/ 'neck' in a phrase-medial position in (27). Recall that the input to this stratum is the output of the word stratum. In this case, this is the intermediate form he?ot (the winner of (24) and (26)), which has undergone word-final devoicing. (27) also demonstrates that a ranking of Ident[Lar] >> $* \mathrm{~V}_{\text {[-voice] }}$ is needed to preserve the devoiced vowel in the underlying final syllable, since it is shifted to the surface penultimate syllable at this stratum and therefore neither satisfies $\left.{ }^{*} \mathrm{~V}_{[+ \text {voice }} \mathrm{C}_{0}\right]_{\text {wd }}$ nor the equivalent

${ }^{3}$ Since it is not the focus of this paper, I always assume the affrication of / $t$ / before [e] in all candidates with the relevant environment. 
constraint on phrase-final syllables to be discussed next. In other words, faithfulness to the input is the only reason that devoicing from the word stratum is retained at the phrase stratum.

(27) $<e>$ epenthesis in phrase-medial he?ot $\rightarrow$ [he?otse] 'neck' (phrase stratum)

\begin{tabular}{|c||l:l|l|l|l|}
\hline he?ot & $*$ CODA] wd & MAX(obs) & DEP & IDLar] & $* V_{\text {[-voice] }}$ \\
\hline \hline a. he?ot & $* !$ & & & & $*$ \\
\hline b. he?o & & $* !$ & & $*$ & $*$ \\
\hline c. he?ogtse & & & $*$ & & $*$ \\
\hline d. he?otse & & & & $* !$ & \\
\hline
\end{tabular}

When words occur in phrase-final positions at this stratum, they must also undergo another round of final devoicing, attributed to a second positional markedness constraint, $\left.{ }^{*} \mathrm{~V}_{[+ \text {voice] }} \mathrm{C}_{0}\right] \mathrm{PhPh}$. The crucial difference between the two domain-final devoicing processes that must still be accounted for is that word-final devoicing only occurs when the vowel is adjacent to a voiceless consonant, whereas phrase-final devoicing can occur in any segmental environment. This has been attributed to two different sources of [-voice]: spreading for word-final devoicing and insertion for phrase-final devoicing. As demonstrated in 4.1, a ranking of DEP $\left.[\mathrm{F}]>>* \mathrm{~V}_{[+ \text {voice }]} \mathrm{C}_{0}\right]_{\mathrm{wd}}$ results in devoicing only when a feature is available to spread. Now, the opposite ranking is needed for phrase-final devoicing: $\left.{ }^{*} \mathrm{~V}_{[+ \text {voice }]} \mathrm{C}_{0}\right]_{\mathrm{PhPh}}>>\mathrm{DEP}[\mathrm{F}]$. This ranking allows the insertion of [-voice], violating DEP[F], in order to satisfy the higher ranked positional markedness constraint. This is illustrated in (28) for /návóómo/ 'I see him.'

(28) Phrase-final devoicing in návóómo $\rightarrow$ [návóómo] 'I see him' (phrase stratum)

\begin{tabular}{|c||l|l|l|l|}
\hline návóómo]PhPh & $\left.* \mathrm{~V}_{[+\mathrm{voice}} \mathrm{C}_{0}\right] \mathrm{PhPh}$ & $\mathrm{Dep}[\mathrm{F}]$ & $\mathrm{ID}[\mathrm{Lar}]$ & $* \mathrm{~V}_{\text {[-voice] }}$ \\
\hline \hline a. návóómo & $* !$ & & $*$ & \\
\hline b. návóómo & & $*$ & $*$ & $*$ \\
\hline
\end{tabular}

Finally, (29) shows a word that ends underlyingly with a voiceless obstruent when it occurs in phrase-final position. As in (27), the input to this tableau has already undergone word-final devoicing. Now, at the phrase stratum, it undergoes $<\mathrm{e}>$ epenthesis and phrase-final devoicing.

(29) $<e>$ epenthesis and phrase-final devoicing in néméhotat $\rightarrow$ [néméhotatse] 'I love you' (phrase stratum)

\begin{tabular}{|c|c|c|c|c|c|c|c|}
\hline néméhotạt & $\left.{ }^{*} \mathrm{CODA}\right]_{\mathrm{wd}}$ & MAX(obs) & DEP & $\left.\mathrm{V}_{[+ \text {voice }]} \mathrm{C}_{0}\right]_{\mathrm{PhPh}}$ & $\operatorname{Dep}[F]$ & ID[Lar] & $* \mathrm{~V}_{\text {[-voice] }}$ \\
\hline a. néméhotạt & $* !$ & & & & & & * \\
\hline b. néméhotå & & $* !$ & & & & & * \\
\hline c. néméhotątse & & & * & $* !$ & & & $*$ \\
\hline d. néméhotạatsę & & & * & & * & $*$ & $* *$ \\
\hline e. néméhotạtse & & & * & & * & $* * !$ & * \\
\hline
\end{tabular}

(29) also illustrates another important constraint ranking. That is, $\left.{ }^{*} \mathrm{CODA}\right]_{\mathrm{wd}}$ and MAX(obstruent) must outrank DEP[F], Ident[Lar], and ${ }^{*} \mathrm{~V}_{\text {[-voice]. }}$. This order eliminates candidates (a) and (b), which violate $\left.{ }^{*} \mathrm{CODA}\right]_{\mathrm{wd}}$ and $\mathrm{MAX}$ (obstruent), respectively, but satisfy $\left.\mathrm{V}_{[+\mathrm{voice}]} \mathrm{C}_{0}\right]_{\mathrm{phPh}}$ without any violations of the lower ranked faithfulness constraints, and with fewer violations of $* \mathrm{~V}_{\text {[-voice] }}$ than the winner. It can also be seen again that Ident[Lar] $\gg * V_{\text {[-voice] }}$ ensures that the now penultimate vowel retains its voicelessness even though it is no longer domain-final. In this case, the result is an output with two voiceless vowels in consecutive syllables, each due to a separate but related domain-final devoicing process. 


\section{Conclusion}

This paper has presented two processes of domain-final vowel devoicing in Cheyenne. One is a canonical case of large domain-final devoicing and is therefore both typologically expected and phonetically grounded. The other occurs word-finally, but due to a post-lexical process of word-final vowel epenthesis, its domainfinal environment is consistently obscured on the surface, and it appears to occur in an arbitrarily restricted, non-final prosodic environment. For this reason, the second process seems at first glance to be neither typologically expected nor phonologically well-motivated. Additionally, unlike the first process, it has no obvious phonetic grounding.

I have nevertheless demonstrated that the two processes can be accounted for in a unified way within Stratal OT, attributing both to the same family of positional markedness constraints that require vowels in domain-final syllables to be voiceless. In fact, I have shown that the only differences between the two domain-final devoicing processes are that a) they occur at different times relative to $<\mathrm{e}>$ epenthesis, and $b$ ) the constraints driving the two processes are ranked differently relative to DEP[F]. The first point is responsible for the surface situation in which vowels devoiced by the word-level process are no longer domain-final on the surface, and the second accounts for the different sources of [-voice] for the two processes. In this way, the word-final process is neither as typologically unexpected nor as phonologically unmotivated as it first appears. Additionally, this analysis sheds light on the phonological relationship between domain-final vowel devoicing processes that occur in different types of segmental environments, which may be extended to accounts of domain-final vowel devoicing other languages.

Finally, while the word-final devoicing process still has no phonetic grounding on its own, I propose that it may be understood as a case of Domain Generalization, whereby an utterance-final phonetically grounded effect becomes phonologized and then generalized to smaller prosodic domains (Myers and Padgett 2014). In fact, given that word-final vowel devoicing is a common cross-linguistic pattern but does not have a phonetic motivation on its own (see Section 2), this may be a viable explanation for these processes crosslinguistically. Interestingly, in Cheyenne, what has been generalized is a preferred surface configuration (i.e. a markedness constraint in my analysis) rather than a specific phonological process. Due to different constraint rankings, the surface preference for voiceless vowels is achieved by different processes at different domains.

\section{References}

Bermúdez-Otero, Ricardo. (2018). Stratal Phonology. In S.J. Hannahs \& A. R. K. Bosch (Eds.), The Routledge Handbook of Phonological Theory (pp. 100-134).

Beckman, Mary. (1996). When is a syllable not a syllable? In T. Otake \& A. Cutler (Eds.), Phonological Structure and Language Processing: Cross-Linguistic Studies (pp. 95-123). Berlin: de Gruyter.

Bogomolets, Ksenia. (2019). Accent and tone in Plains Algonquian languages. In Bogomolets, K. \& H. van der Hulst (eds.). To appear. Word Prominence in Languages with Complex Morphology. Oxford: Oxford University Press.

Chitoran, Ioana \& Edigio Marsico. (2010). Vowel devoicing: an updated phonetic typology. Paper presented at BLS 36.

Chitoran, Ioana \& Khalil Iskarous. (2008). Acoustic evidence for high vowel devoicing in Lezgi. In R. Sock, S. Fuchs \& Y. Laprie (Eds.), Proceedings of the 8th International Seminar on Speech Production, Strasbourg (pp. 93-96).

Cho, Young-Mee Yu. (1993). The phonology and phonetics of 'voiceless' vowels, BLS 19, 64-75.

Dauer, Rebecca. (1980). The reduction of unstressed high vowels in modern Greek. Journal of the International Phonetic Association, 10(1/2), 17-27.

Fisher, Louise, Lenora Holliman, Wayne Leman, Leroy Pine Sr., \& Marie Sanchez. (2019). Cheyenne Dictionary. Chief Dull Knife College. http://www.cheyennelanguage.org/dictionary/ lexicon/index.htm.

Gordon, Matthew. (1998). The phonetics and phonology of non-modal vowels: a crosslinguistic perspective, BLS 24, 93105.

Greenberg, Joseph H. (1969). Some methods of dynamic comparison in linguistics. In J. Puhvel (Ed.), Substance and Structure of Language (pp. 147-203).

Kiparsky, Paul. (2000). Opacity and cyclicity. The Linguistic Review, 17(2-4), 351-366.

Ladefoged, Peter \& Ian Maddieson. (1996). The Sounds of the World's Languages. Cambridge: Blackwell.

Leman, Wayne. (1980). A Reference Grammar of the Cheyenne Language. Museum of Anthropology, University of Northern Colorado, Greeley, Colorado: Occasional Publications in Anthropology, Linguistics Series, No. 5.

Leman, Wayne. (2011). A Reference Grammar of the Cheyenne Language. Lulu Press. An updated version of Leman 1980. 
Leman, Wayne \& Richard Rhodes. (1978). Cheyenne vowel devoicing. In C. Cowan (Ed.), Papers of the Ninth Algonquian Conference, 3-24.

Lipski, John. (1990). Aspects of Ecuadorian Vowel Reduction. Hispanic Linguistics, 4(1), 1-19.

Louie, Meagan. (2010). Variations in vowel devoicing in Northern Paiute. In A. Szakay \& B. Rogers (eds.), The Proceedings of WSCLA 15, University of British Columbia Working Papers in Linguistics (UBCWPL), 165-177.

Milliken, Stuart. (1983). Vowel devoicing and tone recoverability in Cheyenne. In Working Papers of the Cornell Phonetics Laboratory 1, (pp. 43-75).

Myers, Scott \& Jaye Padgett. (2014). Domain generalization in artificial language learning. Phonology, 31(3), 399-433.

Oberly, Stacey \& Viktor Kharlamov. (2015). The phonetic realization of devoiced vowels in the Southern Ute language. Phonetica, 72(1), 1-19.

Selkirk, Elisabeth. (1980). Prosodic domains in phonology: Sanskrit revisited. Juncture, 7, 107-129.

Smith, Caroline L. (2003). Vowel devoicing in contemporary French. Journal of French Language Studies, 13(2), 177194.

Tsuchida, Ayako. (1997). Phonetics and Phonology of Japanese Vowel Devoicing. PhD dissertation. Cornell University.

Tsuchida, Ayako. (2001). Japanese vowel devoicing: Cases of consecutive devoicing environments. Journal of East Asian Linguistics, 10(3), 225-245.

Vaux, Bert. (1998). The laryngeal specifications of fricatives. Linguistic Inquiry, 29(3), 497-511.

Vaux, Bert \& Brett Miller. (2011). The representation of fricatives. In M. van Oostendorp, C.J. Ewen, E.V. Hume, \& K. Rice (Eds.), The Blackwell Companion to Phonology (pp. 669-693).

Vogel, Irene. (1984). On constraining prosodic rules. In H. van der Hulst \& N. Smith (Eds.), Advances in Nonlinear Phonology (pp. 217-23). Dordrecht: Foris Publications.

Walker, James \& Ronald Beline Mendes. (2019). Lower your voice: Vowel devoicing and deletion in Brazilian Portuguese. In S. Calhoun, P. Escudero, M. Tabain, \& P. Warren (Eds.), Proceedings of the 19th International Congress of Phonetic Sciences, Melbourne, Australia 2019 (pp. 3721-3724). 